\title{
Efficacy of Small Group Teaching and its Comparison with Classroom Teaching in the Subject of Dravyaguna
}

\author{
Research Article
}

\section{Meena Shamrao Deogade ${ }^{1^{*}}$, Priti Desai $^{2}$, Prasad KSR $^{3}$}

1. Professor Department of Dravyaguna, 2. HOD, Department of Rachana Sharira, 3. HOD, Department of Panchakarma,

Mahatma Gandhi Ayurved College Hospital and Research Centre, Salod H, Wardha MS - 442001

\begin{abstract}
Background: In Ayurveda, the subject Dravyaguna is with full of nomenclature and multiple aspects of the herb. The student may land in confusion state without proper teaching methods as the recollection of vast material is practically difficult. Educational Researches need to be implemented in Ayurveda and adopted various technologies and methods of Specific Learning should be adopted to overcome these problems.

Materials and Methods: 50 students distributed equally in to two groups observed with a multiple choice questions (MCQs) test and feedback analysis. Graph pad software for paired Student's T test is used for Data Interpretation and final result assessment.

Results: Statistically small group teaching (SGT) for both topic i.e. Haritaki and Amalaki shows the extremely significant result $p=0.0001 .66 \%$ students had given feedback as SGT is better teaching method and $68 \%$ are agreed for implementation of SGT method regularly as teaching learning method. Conclusion: SGT is better teaching method in comparison with Class room teaching (CRT). SGT encourages the students for attentive participation and to achieve the knowledge.
\end{abstract}

Keywords: Ayurveda, Dravyaguna, Small group teaching, Class room teaching, Educational research in Ayurveda.

\section{Introduction}

For the promotion and propagation of Ayurvedic education in this era, there is need to update the ancient knowledge and the system in pace with the development of science without diverting the fundamental principles of Ayurveda. In the wake of progress of Ayurveda on the global platform, education in Ayurveda needs to be redesigned on the basis of the reforms occurring in medical education and also adopt different teaching methods and techniques in other fraternities of medical science (1)

Dravyaguna one of the subject of Ayurveda that deals with the identification of plants approximately 350 in Ayurveda Under graduation) on the basis of morphological characteristics, synonyms, properties viz. taste, properties, potency, post digestive effect, specific action and action of dry or wet herbs, and their therapeutic uses etc.(2). It is very difficult to teach all these through traditional teaching i.e. Class room teaching (CRT) with black-board or LCD as it becomes monotonous. CRT method little bit difficult to complete understanding of information to the learner. The disadvantages of CRT method are many and the

*Corresponding Author:

\section{Meena Shamrao Deogade}

Professor, Department of Dravyaguna,

Mahatma Gandhi Ayurved College Hospital and

Research Centre, Salod H), Wardha MS) - 442001

E-mail ID: drmmeena@,rediffmail.com top amongst it is inability to give personal attention to each and every student. Students are passive and unable to express their ideas unless interrogated or encountered and may go with less of analytical critical thinking.

Thereby it is necessary to adopt "Learner oriented teaching" LOT) in the current education methods and the researches of education thrive for it. Small group teaching SGT) fulfils several important goals of higher education. It encourages students to organize their knowledge by comparing ideas and to make proper interpretations. It offers wide range of expression to their proper understanding of a selected subject eg: Dravyaguna). Thus the SGT has immense importance as a tool for good learning and has extrinsic values too (3).

Similarly in the past, teachers of Ayurveda were committed to propagate the knowledge and pass it on to deserving disciples in small groups. The commitment of preceding teachers and students to their profession is reflected through the pledge in Charaka samhita (4). He followed the methods of symposium and answering the questions raised by the disciples. They used even the methods of debates and discussions in curriculum (5). Knowledge is communicated for selective deserved disciples at rule of six or eight. For example, Agnivesha Tantra Charaka Samhita) taught to 6 students and Sushruta Samhita of Dhanvantari for 8 students. The students and teachers are bound to the rules of education described as Shishyopanayana with a pledge to learn the system under the specified sociological, 
environmental, educational circumstances. The committed 'Gurukula' and Vidyapeeth like Takshasila, Nalanda and Kashi Varanashi) were famous for not only for teaching of Ayurveda but also for various Indian sciences viz. Tarka, Vyakarana, etc.(6).

Dravyaguna, an Ayurveda subject, is with full of nomenclature and multiple knowledge aspects of the herb. The recollection of vast information for the student makes confusion without proper teaching methods. So there is the need to implement innovative teaching method for better understanding, recall and analyzed the subject

\section{Methods}

Ethical clearance: After the clearance from institutional ethical committee study was started. Clearance letter no DMIMS DU)/IEC/2012-13/178 on dated 22.02.2013.

Study design: Simple randomized Comparative crossover observational study. In which a qualitative methodology semi-structured feedbacks) and MCQ was used for data gathering.

Sample size: A sample size of 50 students randomly divided in to two groups. Each 25 in CRT and SGT. 25 students of SGT again divided in 5 small groups of 5 students. The participants are from II-BAMS and the subject of testing is Dravyaguna,

\section{Grouping \\ Haritaki lecture}

i) Group $\mathbf{X}_{1}$ : Students of CRT

ii) Group $\mathbf{X}_{2}$ : CRT Students crossover to SGT

\section{Amalaki lecture}

iii) Group $Y_{1}$ : Students in CRT

iv) Group $Y_{2}$ : CRT Students crossover to SGT

\section{Inclusion criteria:}

All 50 students of II BAMS, who consented were included in the study.

\section{Study duration}

Each CRT is of 60 minutes duration 2 sessions individually for Both Groups)

Each SGT is of 60 minutes duration 2 sessions individually for Both Groups as introduction and explanations by teachers for 30 minutes), Group discussion among each group 20 minutes) and interactions 10 minutes).

\section{Parameters}

MCQs score

Likart scale generated score from feedback form.

\section{Data analysis:}

The assessment was done in between SGT and CRT for both topics on the basis of MCQ by paired Student's t test and feedback analysis.

\section{Procedure adopted for SGT}

- Handouts on both topics prepared as a learning resource material

- Handouts provided and students are allowed to go through the resource materials.

- Teachers explained the topics.

- Students allowed for discussion within the group and interaction with teacher.

- The group discussion is supervised by the faculty.

- 10 MCQs and Feedback format (Likert scale) are used in the assessment.

\section{Result}

The results were based on the cumulative data obtained from the participants of $\mathrm{X}$ and $\mathrm{Y}$ groups for Haritaki and Amalaki lectures in CRT and SGT. The two different lectures Haritaki \& Amalaki) undertaken are compared. At first the MCQ are compared with their understanding and performance. Statistically SGT for both topic i.e. Haritaki and Amalaki shows the extremely significant result $p=0.0001$ Table 1,2 ).

Table 1: Statistical analysis of comparison of marks obtained in MCQ for Haritaki lecture

\begin{tabular}{|l|l|l|l|l|l|l|}
\hline & \multicolumn{1}{|c|}{ Group } & \multicolumn{1}{c|}{ Mean } & $\begin{array}{c}\text { Std. } \\
\text { Deviation }\end{array}$ & $\begin{array}{c}\text { Std. Error } \\
\text { Mean }\end{array}$ & \multicolumn{1}{c|}{$\mathrm{t}$} & \multicolumn{1}{c|}{$\mathrm{p}$ value } \\
\hline \multirow{2}{*}{ Haritaki } & $\mathrm{SGT}\left(\mathrm{X}_{1}\right)$ & 4.72 & 0.61 & 0.12 & \multirow{2}{*}{5.0180} & $\begin{array}{l}0.0001 \\
\text { ES }\end{array}$ \\
\cline { 2 - 7 } & CRT $\left(\mathrm{X}_{2}\right)$ & 4.08 & 0.81 & 0.16 & \\
\hline
\end{tabular}

Table 2: Statistical analysis of comparison of marks obtained in MCQ for Amalaki lecture

\begin{tabular}{|l|l|l|l|l|l|l|}
\hline & \multicolumn{1}{|c|}{ Group } & \multicolumn{1}{c|}{ Mean } & $\begin{array}{c}\text { Std. } \\
\text { Deviation }\end{array}$ & $\begin{array}{c}\text { Std. Error } \\
\text { Mean }\end{array}$ & \multicolumn{1}{c|}{$\mathrm{t}$} & \multicolumn{1}{c|}{$\mathrm{p}$ value } \\
\hline \multirow{2}{*}{ Amalaki } & SGT $\left(\mathrm{Y}_{1}\right)$ & 4.72 & 0.54 & 0.11 & \multirow{2}{*}{4.5476} & \multicolumn{2}{c}{0.0001} \\
$\mathrm{nyyyyyy}$ & $\mathrm{ERT}\left(\mathrm{Y}_{2}\right)$ & 4.00 & 1.22 & 0.24 & \\
\hline
\end{tabular}

ES- Extremely Significant.

Best method of teaching among SGT and CRT analyzed by feedback questionnaires. The Students gave feedback after the completion of SGT and CRT in different sessions. 66\% students agreed for SGT is better teaching learning method and $82 \%$ students accepted that this method created interest, enthusiasm and encouragement for self 
learning. Whereas $64 \%$ students are believed that CRT is passive learning method. $72 \%$ and $76 \%$ students believed that SGT method helped in developing critical thinking and facilitating communication respectively. However $64 \%$ and $68 \%$ students agreed about better learning objectives were achieved with SGT and SGT method should be implemented regularly as teaching learning method respectively Table 3 ).

\begin{tabular}{|c|l|c|c|c|c|c|}
\hline \multicolumn{7}{|c|}{ Table 3: Feedback analysis for analyzing the best teaching method among SGT and CRT } \\
\hline Sr.No. & \multicolumn{1}{|c|}{ Statements } & SD (n) & D (n) & N (n) & A (n) & SA (n) \\
\hline 1 & $\begin{array}{l}\text { SGT is better teaching learning method for this } \\
\text { topic as compared to traditional CRT. }\end{array}$ & 12 & 3 & 2 & 24 & 9 \\
\hline 2 & $\begin{array}{l}\text { SGT process created interest, enthusiasm and en- } \\
\text { couragement for self learning. }\end{array}$ & 0 & 3 & 6 & 28 & 13 \\
\hline 3 & CRT is passive learning method. & 0 & 2 & 16 & 25 & 7 \\
\hline 4 & SGT process helped in developing critical thinking. & 0 & 9 & 5 & 30 & 6 \\
\hline 5 & SGT process helped in facilitating communication. & 0 & 3 & 9 & 30 & 8 \\
\hline 6 & $\begin{array}{l}\text { Learning objectives were achieved better with SGT } \\
\text { as compare to CRT. }\end{array}$ & 0 & 8 & 10 & 27 & 5 \\
\hline 7 & $\begin{array}{l}\text { SGT should be implemented regularly as teaching } \\
\text { learning method. }\end{array}$ & 4 & 10 & 2 & 29 & 5 \\
\hline \multicolumn{7}{|c|}{ SD= Strongly disagree, D= Disagree, N= Neutral, A= Agree, SA= Strongly agree } \\
\hline
\end{tabular}

\section{Discussion}

In SGT teacher encourages the freedom of students and interferes as little as possible. In other words, the teacher is low in demanding, but high in responsiveness. This responsiveness should reflect in CRT management and planning (7). An effective teacher is one who aims to stimulate thinking and facilitate learning rather than convey the knowledge. Thus the teachers need is to learn how to use active learning techniques in design and delivery of their lectures, so that they promote more effective learning in CRT (8) which is a standard model of teaching. In CRT if teachers can increase the one second of silence that usually follows a question to three seconds or more, student answers will reflect more thought and more students will actively participate in the classroom (9). In general the methodological labels assigned to teaching activities are, in themselves, not informative because they refer to a pool of classroom practices which are uniformly used (10).

On the other hand, SGT is increasing in education centers either computer-supported electronic resources (11) or handout method. Small Group Teaching is a "Cooperative learning" with Group discussion, self- evaluation and reviews. When the Group effectively practices in discussion mode it can help to develop the skills such as self-expression, listening collaboration and problem-solving, among students.

Group size can play a significant role in the success of group teaching /learning and the groups of different sizes tend to display quite different dynamics. In a group an agreed set of rules can enhance group management and facilitates knowledge exchange. Interaction in SGT can be divided under three broad headings: content subject material), Task and processes the activities and interpersonal relationships occurring) (12).
The advantage of large group is that more talent and experience available for solving problems or sharing the effort. On the other hand as the size increases, fewer members have the chance to participate, and indeed the differences in relative participation increase to the point where one or two members begin to dominate. Thus it becomes more likely that reticent members will fail to contribute, though they may well enjoy the relative anonymity of a large group.

If the group is small i.e., two or three in number), the tutor is likely to be auxiliary from the beginning. With a large group more than eight) the divergence of aims may push the tutor into a dominant position. However, the use of subgroups can overcome some of the difficulties of a large group. So, in present study have five sub groups of each five students for easy communication and everybody's participation with tutor's trivial position. In smaller group, there are big chances of close relationships, full participation, and consonance of aims. Whereas in a small group or team, leadership and other roles are likely to be shared or rotated, the formation of subgroups, and the increasing differentiation of roles in a large group will ensure the emergence of a leader.

It is observed from the results that the SGT develops the skills of individuals and enriches the knowledge. Teaching and Learning in SGT has a valuable part to play in the all- round education of students. It allows them to negotiate meanings, to express themselves in the language of the subject, and to establish more close contact with academic staff, thereby it develops more instrumental skills of listening, presenting ideas and persuading (13). When the observations are summarized, they reflect the teacher opportunities for better practices through SGT.

To avoid the confusion while recollecting the 
subject Handouts prepared in such a way that it is self explanatory, informative, easily memorable. It is helpful for analyzed the components of Dravyaguna. For example actions and therapeutic uses could be understood on the basis of Rasa, Guna, Veerya, and Vipaka. Thus the present study undertaken is a justification of the multiple aspects incorporated effectively in a learner. In which, the teacher encourages the freedom of students and with no interference in SGT. On the contrary, the teacher provide a great deal of affection and warmth, but little attention and reflective responsiveness in CRT. Dravyaguna CRT management and planning intends to stimulate thinking and facilitate learning in students rather than passing on knowledge. It is for to use active learning techniques in the design and delivery of their lectures so as to promote effective learning in CRT.

It is witnessed from the results that the Dravyaguna SGT develops the skills of individuals and enriches the knowledge. Teaching and Learning in SGT has a valuable part to play in the all- round education of students. It allows them to negotiate meanings, to express themselves in the language of the subject, and to establish more intimate contact with academic staff, thereby developing more instrumental skills of listening, presenting ideas and persuading them (14).

Need based study and updating are two beautiful words to develop the science or to convert it for nothing (15). In Dravyaguna many new terminologies, Botanical names, newly invented chemical constituents, etc., are taught in the lecture. The comprehension is tested through MCQ test in present study and found that the SGT is better than CRT. The results of Haritaki $\left(\mathrm{X}_{2}\right)$ and Amalaki $\left(\mathrm{Y}_{2}\right)$ lectures of SGT is higher than CRT $\left(\mathrm{X}_{1}, \mathrm{Y}_{1}\right)$, expresses that the SGT in both lectures show significance and the SGT have greater value. It is clear from the study that the SGT students learned more applicability of the lectures. As Dravyaguna is the basis of pharmacy and formulations and the lectured Haritaki and Amalaki are in many medicinal compounds, the SGT group expressed that the knowledge given in SGT made them to look in to the product development and helped in emphasis of the compound drugs.

\section{Conclusion}

As concluding remarks it is observed that the methodical CRT is not capable of making a focus on either side of teacher or student, where both of them are in their own way of divergence. The study reveals that the SGT facilitates the student to be attentive and participative to attain and retain the knowledge for further usage. Thus it is clear and evidential from the study that SGT is a better alternative for obtaining knowledge and provides further development in comparison with the classical CRT model.

Thus we can anticipate that the SGT can enrich Verbal- linguistic abilities, Mathematical-logical thinking, Bodily-kinesthetic, Spatial, Intrapersonal and the Interpersonal relationships and it is reflected from interactions with the students.

\section{References}

1. Desai Priti, Case Based Lectures: A New Approach to Teach Basic Sciences in Ayurved Education, JHSE, 2016; 3(1):41-45

2. Deogade MS, Shambharkar N, Kallianpur S, Khobragade P. A Field Survey for the Diverse Flora and Fauna of Chincholi Beat of Vidarbha, Joinsysmed, 2016;4(1): 20-27.

3. Deogade MS, Kethamakka SRP, Panchabai A, Chalakh SP, Desai PR. Perceptions of Dravyaguna students about Small Group Teaching and Classroom Teaching. AAM. 2015; 4(3-4): 67-78.

4. Varier N.V K, History of Ayurveda, Kottakkal: Department of Publications, Aryavaidyasala, 2009: 168-290

5. Varier N.V K, History of Ayurveda, Kottakkal: Department of Publications, Aryavaidyasala, 2009: 168-290

6. Deogade MS, Shambharkar N, Kallianpur S, Khobragade P. A Field Survey for the Diverse Flora and Fauna of Chincholi Beat of Vidarbha, Joinsysmed, 2016;4(1): 20-27.

7. Rowlands A, Abbott S, Bevere G, Roberts C M., Medical students' perceptions and understanding of their specific learning difficulties, International Journal of Medical Education. 2013;4: 200-202

8. Margolin I, Regev H, From Whole Class to Small Groups Instruction: Learners Developing Mathematical Concepts, IUMPST: The Journal. $2011 ; 2: 12$

9. Anonymous, Speaking of Teaching, Stanford university newsletter on teaching, Center for Teaching and Learning, 1999; 10 (2):1

10. Barrow M, McKimm J, Samarasekera D. Strategies for planning and designing medical curricula and clinical teaching, South East Asian Journal of Medical Education, 2010;(4)1: 2-8

11. Anonymous,Joint Committee on Terminology, Report of the 2000 Joint Committee on Health Education and Promotion Terminology, American Journal of Health Education, 2001;32(2): 89- 103

12. Donatelle R, Promoting Healthy Behavior Change, ed 8, Pearson Education, San Francisco, 2009; 4

13. Bradshaw M J and Lowenstein A J, Teaching strategies in Nursing and related health professions, 5th edition; 2011: 53

14. Deogade MS, Shambharkar N, Kallianpur S, Khobragade P. A Field Survey for the Diverse Flora and Fauna of Chincholi Beat of Vidarbha, Joinsysmed, 2016;4(1): 20-27.

15. Prasad KSR, Academic dishonesty in Ayurveda, Joinsysmed 2016; 4(3): 1129-131. 